\title{
Zeolites catalyze the Nazarov reaction and the tert-butylation of alcohols by stabilization of carboxonium intermediates
}

\author{
María Tejeda-Serrano ${ }^{a}$ \\ Sergio Sanz-Navarro ${ }^{a}$ \\ Finn Blakea \\ Antonio Leyva-Pérez*a \\ a Instituto de Tecnología Química, Universidad Politècnica de \\ València, Consejo Superior de Investigaciones Científicas (ITQ, \\ UPV-CSIC), Avda. de los Naranjos s/n, 46022 Valencia, Spain. \\ anleyva@itq.upv.es
}

Click here to insert a dedication.<smiles>[R]C=C([R])C(=O)C([R])=CCCCCCCC</smiles>

Stabilized Carboxonium

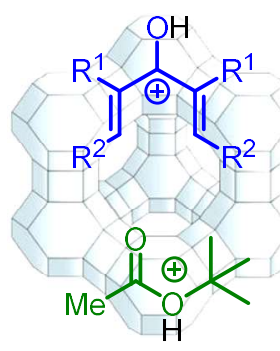

Acid zeolite

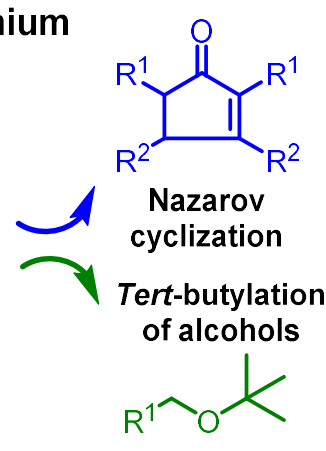

Abstract Zeolites are the most used catalysts worldwide in petrochemistry processes, with particular ability to stabilize carbocations. However, the use of zeolites in organic synthesis is still very scarce. We show here that representative carboxonium-mediated organic reactions, such as the Nazarov cyclization and the tert-butylation of alcohols with tert-butyl acetate, typically performed with very strong acid catalysts in solution such as triflic acid, can be catalyzed by simple zeolites with high yield and selectivity. The aluminosilicate framework stabilizes the intermediate carboxonium species and overrides the need of having superacid protons in solution.

Key words Zeolites, solid catalyst, Nazarov reaction, tert-butylation reaction, carboxonium, heterogeneous catalysis.

Organic reactions catalyzed by very strong acids in solution, either Brönsted acids composed of protons loosely bound to lowcoordinating anions such as sulfuric acid $\left(\mathrm{H}_{2} \mathrm{SO}_{4}\right)$, phosphoric acid $\left(\mathrm{H}_{3} \mathrm{PO}_{4}\right)$ and triflic acid (TfOH), or Lewis acids such $\mathrm{BF}_{3}$ and $\mathrm{AlCl}_{3}$, are recurrent in organic synthesis. ${ }^{1}$ In many cases, the substrates evolve to carbocations and carboxoniums (if the positive charge is stabilized and can delocalize into an adjacent oxygen atom) after the initial protonation, and these charged intermediates are often the key intermediate of the reaction. ${ }^{2}$ Thus, one must accept that the strong acid in solution does not only trigger the reaction but also stabilizes intermediate (oxo)carbocations with the low-coordinating anion left behind, which makes them, in one hand, very efficient and somewhat unique for certain organic reactions while, in the other hand, prove themselves unsuitable to provide mild reaction conditions.

Figure $1 \mathrm{~A}$ shows that the catalytic and stabilizing effect of strong acids in solution for (oxo)carbocations can be somehow mimicked by simple solid acids, despite the acidity of the latter is orders of magnitude lower. ${ }^{3}$ This happens when the success of the organic reaction does not only rely on the first protonation of the substrate but also in the lifetime of the positively charged intermediates. ${ }^{4}$ If so, a solid having a negatively-charged, highlydelocalized framework, can readily interact with the flourishing (oxo)carbocation intermediate and catalyze the reaction to the final product in much milder reaction conditions than soluble superacids.

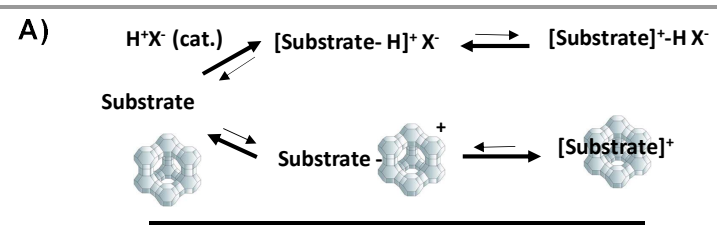

B) Nazarov cyclization

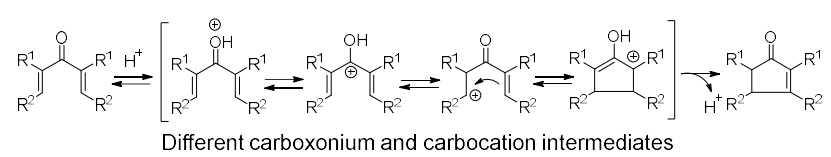

C) Tert-butylation of alcohols

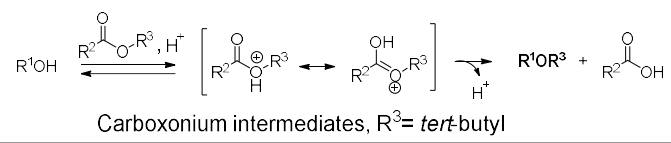

Figure 1 Carboxonium stabilization in solid catalysts. A) Schematic representation of the catalytic action of a soluble superacid and a solid during protonation and (oxo)carbocation stabilization. $\mathrm{X}^{-}$: Low-coordinating anion. B) Carboxonium and carbocation intermediates during the Nazarov cyclization. C) Carboxonium intermediates during the tert-butylation of alcohols.

Zeolites are crystalline microporous aluminosilicates with the general formula shown in Figure 2.5 The isomorphic substitution of $\mathrm{Si}^{4+}$ by $\mathrm{Al}^{3+}$ atoms, generates a defect of positive charges in the framework that must be balanced with external cations, and if these cations are protons, the zeolite shows Brönsted acidity. The negatively charged zeolite framework acts as a very diffuse macro-anion, in analogy with low-coordinating anions in solution. Thus, a zeolite may be active as acid catalyst in relatively complex organic reactions involving positively charged intermediates, and substitute very strong soluble acids. Indeed, this strategy has proved efficient in organic reactions involving highly-delocalized aromatic carbocations. 4,6 However, it is 
difficult to find in the literature simple solid acids that catalyze relatively complex organic reactions involving carboxonium intermediates. $^{7}$

$$
\mathrm{M}_{2 / n} \mathrm{O} . \mathrm{Al}_{2} \mathrm{O}_{3} \cdot x \mathrm{SiO}_{2} \cdot y \mathrm{H}_{2} \mathrm{O}
$$

Figure 2 General formula for zeolites. $\mathrm{M}$ is a hydrogen, alkali or alkaline earth atom, $n$ is the charge of that atom, $x$ is the ratio of $\mathrm{SiO}_{2} / \mathrm{Al}_{2} \mathrm{O}_{3}$ and $y$ is the number of water molecules.

Figures $1 \mathrm{~B}$ and $1 \mathrm{C}$ show two representative organic reactions involving carboxonium intermediates, the Nazarov cyclization ${ }^{8}$ and the tert-butylation of alcohols, ${ }^{9}$ respectively. The former is typically catalyzed by very strong soluble acids, for instance $\mathrm{TfOH},{ }^{10}$ and starts with the protonation of a dienone in transtrans configuration, which after several delocalizations of the positive charge evolves to the cyclized product. The very strong acid catalyst does not only trigger the reaction but also may isomerize the starting dienone in other conformations to the required trans-trans configuration. ${ }^{11}$ While a zeolite will not trigger so efficiently the reaction, it may stabilize the different positively charged intermediate species formed during reaction, in such a way to perform the cyclization efficiently. ${ }^{12}$

Figure 3 shows the catalytic results for the Nazarov cyclization with H-USY zeolite (commercially available as CBV-720), a standard acid zeolite of $\mathrm{Si} / \mathrm{Al}$ ratio $=15$, a pore diameter of $\sim 10 \AA$

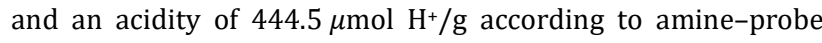
titrations (Table S1). ${ }^{4,13 a}$ It can be seen that dienones 2a-c cyclize in high yields with just $0.5 \mathrm{~mol} \%$ solid acid sites $(10 \mathrm{wt} \%$ in zeolite) after $2 \mathrm{~h}$ reaction time at $75 \stackrel{\circ}{ } \mathrm{C}$ (see below comments for products 2d-e). Remarkably, the cis-cis isomer was obtained as the major product, since kinetic results by gas chromatography coupled to mass spectrometry (GC-MS) show that the other isomers appear at the very beginning of the reaction but evolve progressively to the cis-cis isomer, as assessed with independently synthesized pure samples of the product.11 It must be recognized that the substrate scope is quite narrow, however, not far from other catalytic system based on stronger acids. ${ }^{13 \mathrm{~b}}$

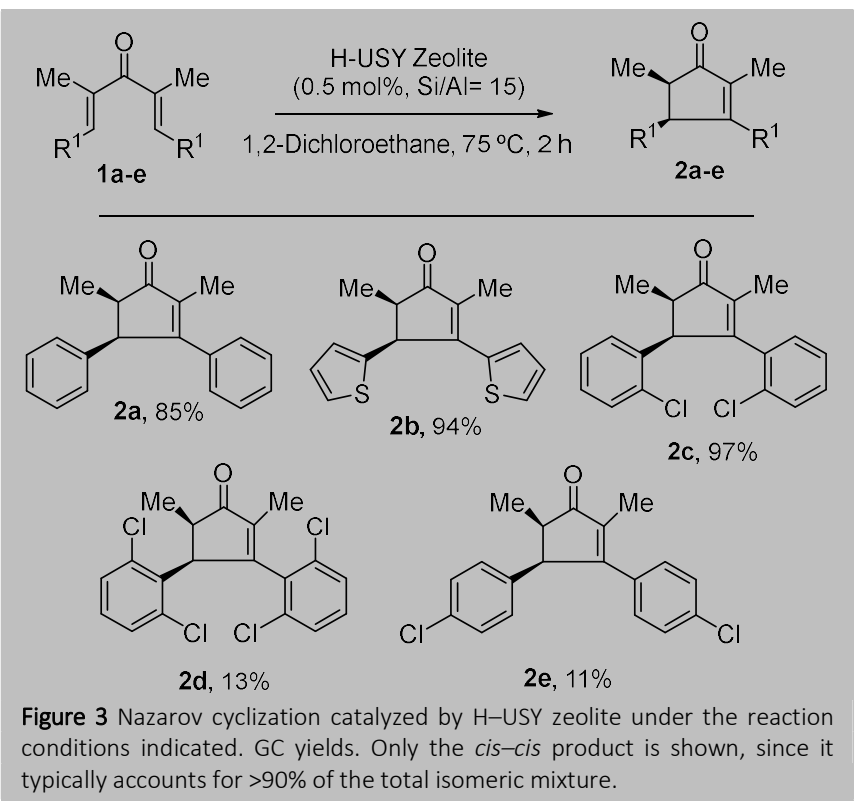

Figure 4 shows a plot where the activation energy (Ea) for the Nazarov cyclization of dienone $\mathbf{1 a}$ is represented $v s$. the acidity (tabulated pKa values) of different soluble and solid acids.4,6c The activation energy was calculated from the initial rate of the cyclization at different temperatures, which was obtained by linear regression of the first points of the corresponding kinetics (Figure S1), then applying the Arrhenius equation. The results clearly show that, for soluble acids, the activation energy correlates linearly with the pKa of the acid, as it would be expected for general acid catalysis where the protonation step is the limiting step of the reaction (see Figure $1 \mathrm{~A}$ ). In striking contrast, different zeolites show a much lower activation energy than that expected from their corresponding $\mathrm{pKa}$ values, at least $40 \mathrm{kcal}$ lower. This decrease in activation energy is more pronounced as the acid strength of the zeolite increases (i.e compare H-USY 720 with 760) and it does not depend on zeolite pore size or topology, since the Beta-H and ZSM-5-H zeolites also catalyze well the cyclization.

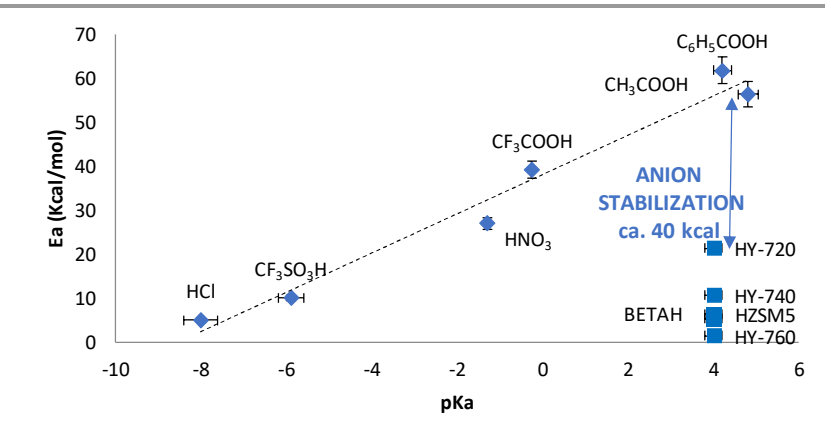

Figure 4 Activation energy (Ea) for the Nazarov cyclization of dienone 1a as a function of the acidity (pKa) of different soluble and solid acids. The Si/Al ratios for the different zeolites is: HY-720, BETA-H and ZSM-5 15, HY-740 20, and HY-760 30. Error bars account for a 5\% uncertainty.

When the activation energy is decoupled into the enthalpic and entropic contributions (Figures S2-S3), it can be seen that the decrease in the activation energy is enthalpic in nature.14 Comparison of the activation energies for 1a-c, with different zeolites (Figures S4-S7), shows an increase with the electron withdrawing nature of the substituents, in other words, the more delocalized dienones react worse. This can be the reason why dienones 2d-e did not cyclize significantly under all conditions tested. Single crystal X-ray crystallography of dienone 1e (Figure S8) did not show any particular structural issue to justify such a huge difference in reactivity, and the use of the aluminosilicate MCM-22 as a catalyst (the non-porous analogue of H-USY) did not improve the yield of $\mathbf{2 d}$ (Figure S9). These results confirm that the catalytic action of the zeolites for the Nazarov reaction depends on electronics rather than in sterics, and that very subtle changes in the electronics of the dienone dramatically changes the cyclization outcome. Indeed, in the case of $\mathbf{1 d}$, only the isomerization of the starting dienone to non-productive isomers, was found, and calculation of the dynamic radii by molecular mechanics (MM2) at minimized energy for this and other dienone isomers, gives values of $\sim 15 \AA$, nearly one and a half higher that the pore diameter of H-USY zeolite (Figure S9). Thus, the Nazarov cyclization must occur outside the pores, in the outer surface of the microporous of the zeolite. To check this, the aluminosilicate MCM-22 was used as a catalyst for 1a, and a similar activation energy to H-USY was obtained. These results strongly support that the Nazarov cyclization is catalyzed on the negatively-charged surface of the zeolite by electronic 
stabilization of the carboxonium and carbocations intermediates during reaction, and not to confinement effects within the pores. ${ }^{15}$

The catalytic zeolite was recovered and recycled after the Nazarov cyclization of 1a (Figure S10). Thermogravimetric analysis of the used solid catalyst showed a significant amount $(\sim 8 \%)$ of non-volatile carbonaceous substances retained in the zeolite, even after extensive washings (Figure S11), and Fouriertransformed infrared spectroscopy (FT-IR, Figure S12) of the used catalyst showed the appearance of new signals around 1650-1700 $\mathrm{cm}^{-1}$, which corresponds to entrapped aromatic organic compounds. ${ }^{16}$ These results, together, indicate the strong adsorption of colored aromatic intermediates, most probably positively charged species, on the zeolitic surface.

Figure 5 shows a one-pot Friedel-Crafts/ Nazarov cyclization ${ }^{17}$ catalyzed by the most active H-USY zeolite (CBV740), where the dihydroxylation of a propargyl alcohols 3a-c with mesitylene 4 gives directly the all-carbon product indene $\mathbf{6 a - c}$ in 42 to $69 \%$ yields, without the need of isolating intermediates $\mathbf{5 .}^{6 a, 18}$ These resulst illustrate the potential of zeolites as catalysts for the Nazarov reaction. However, it must be noticed that, while intermediate $\mathbf{5 a}$ is formed with just $1 \mathrm{~mol} \%$ of acid zeolitic sites in $78 \%$ under similar reaction conditions, ${ }^{19}$ the cyclization needs $10 \mathrm{~mol} \%$ of zeolite to convert $\sim 80 \%$ of this intermediate, even with the more active $\mathrm{H}-\mathrm{USY}(\mathrm{Si} / \mathrm{Al}=20)$ zeolite.

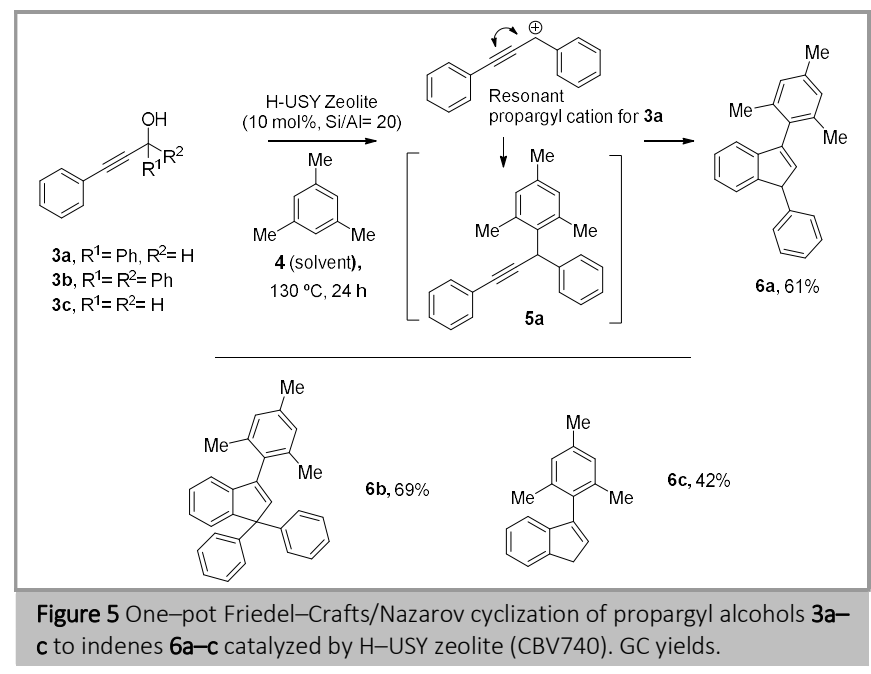

The tert-butylation of benzyl alcohols $\mathbf{7 a - j}$ with tert-butyl acetate $\mathbf{8}$, another representative carboxonium-mediated organic reaction (see Figure 1C), was then attempted with zeolite catalysts. ${ }^{9}$ Figure 6 shows that the different benzyl alcohols give in good yields a variety of tert-butylated products containing halide (9b-f), trifluomethyl (9b), alcohol (9d), thiol (9h-i) and cyano(9j) functional groups, in different positions of the aromatic ring, when a H-USY catalyst was employed. Not only that, alkyl (products 9k-o) and homoallyl (products 9p-s) alcohols also engage in the reaction, although the latter provided somewhat lower yields due to extensive dehydration to the corresponding styrene derivatives, under the indicated reaction conditions.

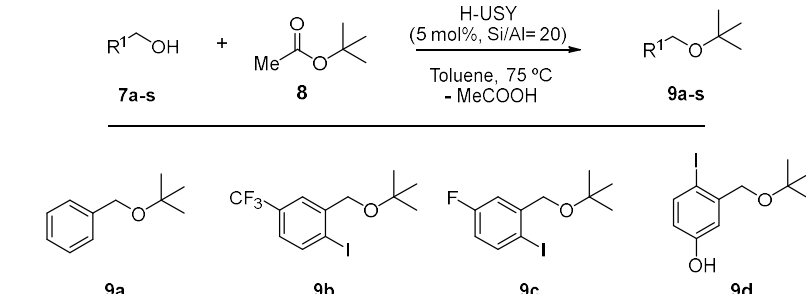<smiles>CC(C)(C)OCc1cc(I)c(COC(C)(C)C)cc1I</smiles>

$55 \%$

$9 \mathrm{c}$
$85 \%$

$79 \%$
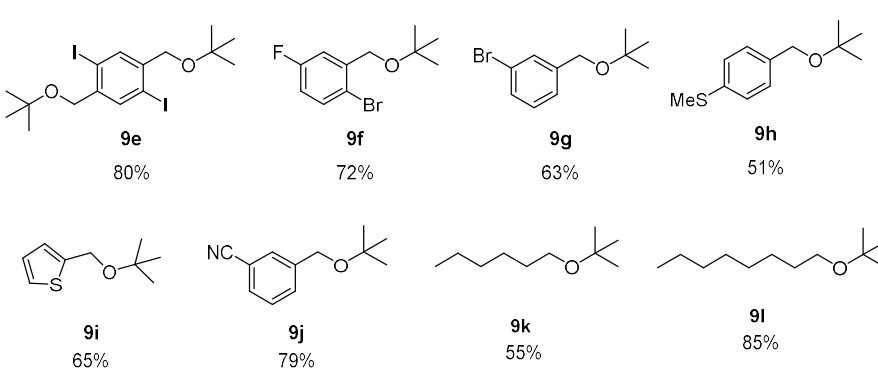

$55 \%$

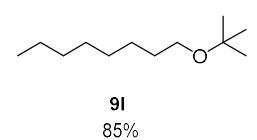

$\overbrace{\substack{9 \mathrm{~m} \\ 75 \%}}$<smiles>CC(C)(C)OC1CCCCC1</smiles><smiles>CC(C)(C)OCC1CCCCC1</smiles>

$85 \%$<smiles>CC(C)(C)OCCc1ccc([N+](=O)[O-])cc1</smiles>

$45 \%$

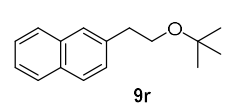

$55 \%$
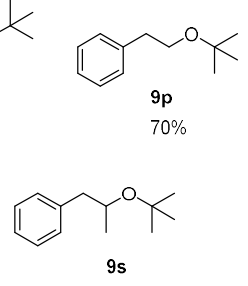

$65 \%$
Figure 6 Tert-butylation of benzyl, alkyl and homoallyl alcohols 7a-s with tertbutyl acetate 8 catalyzed by H-USY zeolite (CBV740).

Figure 7 shows a plot with the calculated activation energies for the tert-butylation of benzyl alcohol $\mathbf{7 a}$ with tert-butyl acetate $\mathbf{8}$, in the presence of different soluble and solid acids. As for the Nazarov reaction, the solid acids show a significant decrease in the activation energy compared to soluble acids, the latter showing a linear correlation. As it occurs in the Nazarov reaction, not only zeolites but also other aluminosilicates such as MCM-22 and the mesoporous material MCM-41, efficiently catalyzes the reaction, which suggests that the reaction occurs on the external surface of the zeolite.

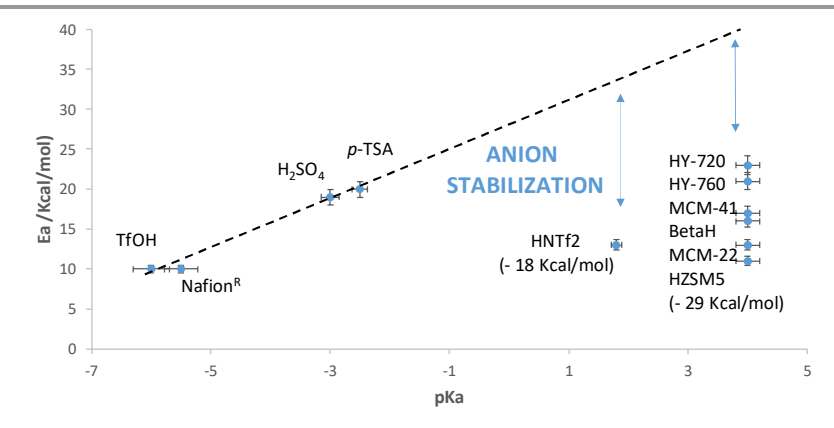

Figure 7 Correlation between the activation energy (Ea) and the acidity ( $\mathrm{pKa}$ ) of different soluble and solid acids for the tert-butylation of benzyl alcohol 7a with tert-butyl acetate 8 to give the ether product 9a. Error bars account for a $5 \%$ uncertainty.

In conclusion, carboxonium and carbocation-mediated reactions are efficiently catalyzed by acid aluminosilicates, particularly zeolites, under relatively mild conditions. The catalysis occurs on the surface of the zeolite, thus molecular size is not a restriction and the most important factor governing the reactions is the electronics of the substrate. These results open new 
opportunities in the design of organic reactions based on cheap, widely available and environmentally-friendly solid catalysts to substitute corrosive soluble acids. ${ }^{20}$

All chemicals were of reagent grade quality. They were purchased from commercial sources and used as received. Gas chromatographic analyses were performed in an instrument equipped with a $25 \mathrm{~m}$ capillary column of $5 \%$ phenylmethylsilicone. $N$-dodecane was used as an external standard. GC/MS analyses were performed on a spectrometer equipped with the same column as the GC and operated under the same conditions. ${ }^{1} \mathrm{H},{ }^{13} \mathrm{C}$ and DEPT NMR spectra were recorded at room temperature on a Bruker AC 300 using the appropriate solvent containing TMS as an internal standard. FT-IR spectra were recorded on a Perkin-Elmer 882 spectrophotometer as $\mathrm{KBr}$ pellets or on a Thermo Nicolet iS10 after deposition and evaporation of a solution of the compound over a germanium wafer. Absorption spectra were recorded on a Cary 300 UVVis spectrophotometer (Varian). The thermogravimetric analyses were performed under a dry $\mathrm{N}_{2}$ atmosphere with a Mettler Toledo TGA/STDA $851^{\mathrm{e}}$ thermobalance operating at a heating rate of $10{ }^{\circ} \mathrm{C} \mathrm{min}^{-1}$. Crystallographic data for compound $\mathbf{1 e}$ have been deposited in The Cambridge Crystallographic Data Centre free of charge, with accession code CCDC reference number 1981152.

\section{Procedures}

Synthesis of dienones 1a-e. ${ }^{20 \mathrm{c}} 6.9 \mathrm{~g}$ of $\mathrm{KOH}$ pellets were weighed into a beaker and $20 \mathrm{ml}$ of distilled water was slowly added. The mixture was stirred to dissolve the $\mathrm{KOH}$. This solution was added to a second flask equipped with a magnetic stirrer and containing $40 \mathrm{ml}$ of methanol, 6.15 $\mathrm{ml}$ of 3-pentanone and $122 \mathrm{mmol}$ of the corresponding aldehyde. The conical flask was then placed into a silicon bath set at $100^{\circ} \mathrm{C}$ and connected to a condensation unit to achieve reflux. The reaction was refluxed overnight. After the reaction, the solution was neutralised by slowly adding $61 \mathrm{ml}$ of $2 \mathrm{M}$ hydrochloric acid. After neutralisation, the aqueous phase and the organic phase were separated using a titre set up. The solution was poured into the titre along with $20 \mathrm{ml}$ of dichloromethane (DCM) and shaken to allow the phases to mix. After phase separation and the aqueous phase discarded, the process was repeated twice, and also with $20 \mathrm{ml}$ of sodium bicarbonate solution, $40 \mathrm{ml}$ of water and finally $20 \mathrm{ml}$ of brine. The final organic solution was dried over sodium sulphate, filtered, and concentrated under vacuum. The product was purified by crystallisation by dissolving in methanol and leaving the solution to cool overnight. The pure crystals were tested in the GC using a general 10-minute method with single injection of $3 \mu$. The sample was then tested using mass spectroscopy to ensure that the correct product had been afforded.

\section{Compound 1a.}

IR $\left(\mathrm{cm}^{-1}\right): 1606,1441$.

${ }^{1} \mathrm{H} \mathrm{NMR}\left(\mathrm{CDCl}_{3}, 300 \mathrm{MHz}\right): \delta=7.46-7.32(\mathrm{~m}, 10 \mathrm{H}), 7.23(\mathrm{~s}, 2 \mathrm{H}), 2.23(\mathrm{~s}$, $6 \mathrm{H})$.

${ }^{13} \mathrm{C}$ NMR $\left(\mathrm{CDCl}_{3}, 75 \mathrm{MHz}\right): \delta=202.14,139.09,137.04,136.10,129.74$, $128.58,128.40,15.04$.

MS: $m / \mathrm{z}(\%)=\mathrm{M}^{+} 262(60), 116(100)$.

Anal. Calcd for 1a: C, 85.67; H, 8.32. Found: C, 85.85; H, 6.82.

\section{Compound 1c.}

IR ( $\left.\mathrm{cm}^{-1}\right): 1635,1470,1435$.

${ }^{1} \mathrm{H} \mathrm{NMR}\left(\mathrm{CDCl}_{3}, 300 \mathrm{MHz}\right): \delta=7.35(\mathrm{t}, \mathrm{J}=9.8 \mathrm{~Hz}, 6 \mathrm{H}), 7.24-7.18(\mathrm{~m}, 4 \mathrm{H})$, $2.00(\mathrm{~s}, 6 \mathrm{H})$.

${ }^{13} \mathrm{C}$ NMR $\left(\mathrm{CDCl}_{3}, 75 \mathrm{MHz}\right): \delta=201.54,138.87,136.87,135.10,134.61$, $130.88,130.15,129.91,127.05,15.12$.

MS: $m / \mathrm{z}(\%)=\mathrm{M}^{+} 330(3), 295$ (45), 150 (70).

Anal. Calcd for 1c: C, 68.07; H, 6.01. Found: C, 69.01; H, 4.78.
Compound 1d.

IR ( $\left.\mathrm{cm}^{-1}\right): 1718,1642,1423$.

${ }^{1} \mathrm{H} \mathrm{NMR}\left(\mathrm{CDCl}_{3}, 300 \mathrm{MHz}\right): \delta=7.31(\mathrm{~s}, 1 \mathrm{H}), 7.29(\mathrm{~s}, 2 \mathrm{H}), 7.20-7.12(\mathrm{~m}$, $5 \mathrm{H}), 1.79(\mathrm{~s}, 6 \mathrm{H})$.

${ }^{13} \mathrm{C}$ NMR $\left(\mathrm{CDCl}_{3}, 75 \mathrm{MHz}\right): \delta=199.39,141.10,134.49,134.40,134.29$, $129.55,128.09,14.80$.

MS: $m / \mathrm{z}(\%)=\mathrm{M}^{+} 400(2), 277$ (100), 199 (50).

Anal. Calcd for 1d: C, 56.47; H, 4.49. Found: C, 57.10; H, 3.28.

Compound 1e.

IR ( $\left(\mathrm{cm}^{-1}\right):$ 1678, 1622, 1487.

$\left.{ }^{1} \mathrm{H} \mathrm{NMR} \mathrm{(CDCl}, 300 \mathrm{MHz}\right): \delta=7.37(\mathrm{~s}, 8 \mathrm{H}), 7.12(\mathrm{~s}, 2 \mathrm{H}), 2.18(\mathrm{~s}, 6 \mathrm{H})$.

${ }^{13} \mathrm{C} \mathrm{NMR}\left(\mathrm{CDCl}_{3}, 75 \mathrm{MHz}\right): \delta=201.49,137.70,137.50,137.42,134.38$, $130.97,128.84,15.05$.

MS: $m / \mathrm{z}(\%)=\mathrm{M}^{+} 330$ (3), 295 (45), 150 (70), 115 (100).

Anal. Calcd for 1e: C, 68.07; H, 6.01. Found: C, 69.01; H, 4.78.

Zeolite-catalyzed Nazarov cyclization. The corresponding amount of dienone 1a-e $(0.2 \mathrm{mmol})$ was weighed and diluted with $1 \mathrm{ml}$ of dichloroethane (DCE) in a test tube. A $50 \mu \mathrm{l}$ sample was taken as the zerotime sample and diluted in a vial with $1 \mathrm{ml}$ of ethyl acetate to be analysed using GC, with $n$-dodecane as an external standard ( $22 \mu \mathrm{l}, 0.1 \mathrm{mmol})$. The substrate and DCE were then added to a vial containing $0.5 \%$ mole $\mathrm{H}^{+}$of the zeolite ( $5 \mathrm{wt} \%$ for $1 \mathrm{a}$ ) and a magnetic stirrer. The vial was placed in a silicon bath at the required reaction temperature, ranging from 25 to 75 ${ }^{\circ} \mathrm{C}$. The reaction was typically run for 120 minutes and $50 \mu \mathrm{l}$ samples were taken throughout the reaction, and placed in a vial with $1 \mathrm{ml}$ of ethyl acetate. Samples were then filtered to remove any solid catalyst in the sample, and then analysed by GC using adding $n$-dodecane as an external standard $(22 \mu \mathrm{l}, 0.1 \mathrm{mmol})$. All the products are reported and characterized in the literature: $\mathbf{2 a - d}{ }^{13 b} ; \mathbf{2} \mathbf{e}^{21 a}$

Recovery and reuse of the catalyst. The Nazarov cyclisation was performed using the same method as above except with double the amount of catalyst ( $1 \mathrm{~mol} \%, 10 \mathrm{wt} \%)$ to ensure a good recovery. The reaction chosen to test the reusability of the catalyst was the cyclisation of $2 \mathbf{c}$ at $75{ }^{\circ}$. After 60 minutes, the reaction was stopped and the zeolite separated from the solution using a centrifuge at $6000 \mathrm{rpm}$. After separation, the zeolite was cleaned with a solvent and separated again in the centrifuge. The process was repeated twice. Then, the zeolite was left to dry overnight, weighed and used again in reaction, adjusting the mass of substrate and volume of DCE to keep the same final concentration.

Zeolite-catalyzed one-pot Friedel-Crafts/Nazarov cyclization. ${ }^{17 c}$ Alcohol $3(0.125 \mathrm{mmol}, 32 \mathrm{mg})$ was weighed into a $2 \mathrm{ml}$ vial and diluted with $1 \mathrm{ml}$ of mesitylene 4 . The corresponding zeolite $(10 \mathrm{~mol} \%, 100 \mathrm{wt} \%)$ was added and the vial was capped and placed in a steel heat block at 130 ${ }^{\circ} \mathrm{C}$. A $50 \mu \mathrm{l}$ sample was taken after 30,60 and 90 minutes and then the reaction was left to run overnight. The samples were diluted with $1 \mathrm{ml}$ of dichloromethane, filtered to remove any solid catalyst in the sample and analysed by GC after adding $n$-dodecane as an external standard $(22 \mu \mathrm{l}, 0.1$ $\mathrm{mmol})$. All the products are reported and characterized in the literature: 6a-c. ${ }^{17 \mathrm{c}}$

Zeolite-catalyzed tert-butylation of alcohols. The corresponding amount of alcohols $\mathbf{7 a - s}(0.4 \mathrm{mmol})$ was weighed, then the corresponding amount of tert-butyl acetate $8(68 \mu l, 0.5 \mathrm{mmol})$. and $0.5 \mathrm{ml}$ of toluene in a test tube were added. A $20 \mu$ sample was taken as the zero-time sample and diluted in a vial with $1 \mathrm{ml}$ of ethyl acetate to be analysed using GC, with $n$-dodecane as an external standard $(22 \mu \mathrm{l}, 0.1 \mathrm{mmol})$. The mixture was then added to a vial containing $5 \mathrm{~mol} \% \mathrm{H}^{+}$of the zeolite $(50 \mathrm{wt} \%$ for 7a) and a magnetic stirrer. The vial was placed in a silicon bath at $75^{\circ} \mathrm{C}$. The reaction was typically run for 240 minutes and $20 \mu \mathrm{l}$ samples were taken throughout the reaction, and placed in a vial with $1 \mathrm{ml}$ of ethyl acetate. Samples were then filtered to remove any solid catalyst in the sample, and then analysed by GC adding $n$-dodecane as an external 
standard $(22 \mu \mathrm{l}, 0.1 \mathrm{mmol})$. Most of the products are reported and characterized in the literature: $9 \mathbf{a}^{21 b} ; \mathbf{9 g},{ }^{21 c} ; \mathbf{9 h},{ }^{21 d} ; \mathbf{9 i},{ }^{21 e} ; \mathbf{9 k - 1}, \mathbf{9 n},{ }^{21 f}$; 9m, ${ }^{21 \mathrm{~g} ;}$ 9o, ${ }^{21 \mathrm{~h}} ; \mathbf{9 p}, 9 \mathbf{9} ;{ }^{21 \mathrm{i}} ; \mathbf{9 q}{ }^{21 \mathrm{j}} ; \mathbf{9 r}{ }^{21 \mathrm{k}}$

\section{Funding Information}

This work was supported by the MINECO (Spain) (Projects CTQ 201786735-P, RTC-2017-6331-5, and Severo Ochoa program SEV-20160683).

\section{Acknowledgment}

M. T.-S. thanks ITQ for the concession of a contract. S. S.-N thanks MINECO for the concession of a FPI fellowship. F. B. acknowledges financial support from the Erasmus programme and is grateful to the University of Strathclyde for a short stay at ITQ. Authors would like to thank the use of RIAIDT-USC analytical facilities.

\section{Supporting Information}

YES (this text will be updated with links prior to publication)

\section{Primary Data}

NO (this text will be deleted prior to publication)

\section{References}

(1) (a) Antoniotti, S.; Dalla, V.; Duñach, E. Angew. Chem. Int. Ed. 2010 49, 7860. (b) Cabrero-Antonino, J. R.; Tejeda-Serrano, M.; Quesada, M.; Vidal-Moya, J. A.; Leyva-Perez, A.; Corma, Chem. Sc. 2017, 8, 689.

(2) Naredla, R. R.; Klumpp, D. A. Chem. Rev. 2013, 113, 6905.

(3) Losch, P.; Joshi, H. R.; Vozniuk, O.; Grünert, A.; Ochoa-Hernández, C.; Jabraoui, H.; Badawi, M.; Schmidt, W. J. Am. Chem. Soc. 2018.

(4) Cabrero-Antonino, J.; Leyva-Pérez, A.; Corma, A. Angew. Chem. Int. Ed. 2015, 54, 5658

(5) (a) Corma, A.; Garcia, H. Chem. Rev. 2003, 103, 4307. (b) Corma, A J. Catal. 2003, 216, 298

(6) (a) Nursahedova S. K.; Zerov, A. V.; Boyarskaya, I. A.; Grinenko, E. V.; Nenajdenko, V. G.; Vasilyev, A. V. Org. Biomol. Chem. 2019, 17, 1215. (b) Nursahedova S. K.; Ryabukhin, D. S.; Muzalevskiy, V. M.; Iakovenko, R. O.; Boyarskaya, I. A.; Starova, G. L.; Nenajdenko, V. G.; Vasilyev, A. V. Eur. J. Org. Chem. 2019, 1293. (c) Rivero-Crespo, M. A.; Tejeda-Serrano, M.; Perez-Sanchez, H.; Ceron-Carrasco, J. P.; Leyva-Perez, A. Angew. Chem. Int. Ed. 2020, 2020, 59, 3846.

(7) (a) Luzgin, M. V.; Romannikov, V. N.; Stepanov, A. G.; Zamaraev, K. I. J. Am. Chem. Soc. 1996, 118, 10890. (b) Ha, K.-S.; Lee, Y.-J.; Bae, J. W.; Kim, Y. W.; Woo, M. H.; Kim, H.-S.; Park, M.-J.; Jun, K.-W. Appl. Catal. A 2011, 395, 95.

(8) (a) He, W.; Sun, X.; Frontier, A. J. J. Am. Chem. Soc. 2003, 125, 14278 (b) Alachouzos, G.; Frontier, A. J.; Angew. Chem. Int. Ed. 2017, 56, 15030.

(9) Lloret, V.; Rivero-Crespo, M. A.; Vidal-Moya, J. A.; Wild, S.; Domenech-Carbo, A.; Heller, B. S. J.; Shin, S.; Steinrueck, H.-P.;
Maier, F.; Hauke, Frank; Varela, M.; Hirsch, A.; Leyva-Perez, A.; Abellan, G. Nat. Commun. 2019, 10, 1.

(10) Vaidya, T.; Eisenberg, R.; Frontier, A. J. ChemCatChem 2011, 3 , 1531.

(11) He, W.; Herrick, I. R.; Atesin, T. A.; Caruana, P. A.; Kellenberger, C. A.; Frontier, A. J. J. Am. Chem. Soc. 2008, 130, 1003.

(12) Lewis, J. D.; Van de Vyver, S.; Román-Leshkov, Y. Angew. Chem. Int. Ed. 2015, 54, 9835.

(13) (a) Derouane, E.; Védrine, J.; Pinto, R.; Borges, P.; Costa, L.; Lemos, M.; Lemos, F.; Ribeiro, F. Catal. Rev. 2013, 55, 454. (b) Daneshfar Z.; Rostami, A. RSC Adv. 2015, 5, 104695.

(14) Kadam, S. A.; Li, H.; Wormsbecher, R. F.; Travert, A. Chem. Eur. J. 2018, 24, 5489.

(15) (a) Huang, C.; Zhang, Y.; Yang, H.; Wang, D.; Mi, L.; Shao, Z.; Liu, M.; Hou, H. Crystal Growth \& Design 2018, 18 (9), 5674-5681. (b) Shao, Z.; Liu, M.; Dang, J.; Huang, C.; Xu, W.; Wu, J.; Hou, H. Inorg. Chem. 2018, 57 (16), 10224-10231.

(16) Reale, E.; Leyva, A.; Corma, A.; Martinez, C.; Garcia, H.; Rey, F. J. Mater. Chem. 2005, 15, 1742.

(17) (a) Liu, R.; Abu Sohel, S.; Lin, S. Synlett 2008, 5, 745. (b) Somai Magar, K.; Lee, Y. Org. Lett. 2013, 15, 4288. (c) Morita, N.; Miyamoto, M.; Yoda, A.; Yamamoto, M.; Ban, S.; Hashimoto, Y.; Tamura, O.; Tetrahedron Lett. 2016, 57, 4460.

(18) Clegg, N.; Paruthiyil, S.; Leitman, D.; Scanlan, T. J. Med. Chem. 2005, $48,5989$.

(19) (a) Armengol, E.; Corma, A.; Garcia, H.; Jaime, P. Appl. Catal. A 1995 126, 391. (b) Cantín, Á.; Gomez, M. V.; de la Hoz, A.. Beilstein J. Org. Chem. 2016, 12, 2181-2188. (c) Martínez-Gualda, A. M.; Cano, R.; Marzo, L.; Pérez-Ruiz, R.; Luis-Barrera, J.; Mas-Ballesté, R.; Fraile, A.; A. de la Peña O'Shea, V.; Alemán, J. Nat. Commun. 2019, 10, 2634.

(20) (a) Cabrero-Antonino, J. R.; Leyva-Perez, A.; Corma, A. Chem. Eur. J. 2012, 18, 11107. (b) Cabrero-Antonino, J. R.; Leyva-Perez, A.; Corma, A. Chem. Eur. J. 2013, 19, 8627.

(21) (a) Paul, N.; Kaladevi, S.; Beneto, A. J.; Muthusubramanian, S.; Bhuvanesh, N. Tetrahedron Lett., 2012, 68, 6892. (b) Rai, N. P.; Arunachalam, P. N. Synth. Commun., 2007, 37, 2891. (c) Zhao, L.; Liu, B.; Tan, Q.; Ding, C-H.; Xu, B. Org. Lett., 2019, 21, 9223. (d) Julie Guiard, J.; Yaniss Rahali, Y.; Praly, J-P. Eur. J. Org. Chem., 2014, 4461. (e) Chandrasekhar, S.; Rajaiah, G.; Chandraiah, L.; Narsimha D.S. Synlett, 2001, 11, 1779. (f) Mallesha, N.; Prahlada Rao, S.; Suhas, R.; Channe Gowda, D. Tetrahedron Lett., 2012, 53, 641. (g) Wright, S.; Hageman, D.; Wright, A.; McClure, L. Tetrahedron Lett., 1997, 38, 7345. (h) Liu, Y.; Wang, X.; Wang, Y.; Du, C.; Shi, H.; Jin, S.; Jiang, C.; Xiao, J.; Cheng, M. Adv. Synth. Catal., 2015, 357,1029. (i) Salvati, A. E.; Hubley, C. T.; Albiniak, P. A. Tetrahedron Lett., 2014, 55, 7133. (j) Suzuki, H.; Takeuchi, T.; Mori, T. J. Org. Chem. 1996, 61, 5944. (k) Li, Q.; Liskey, C. W.; Hartwig, J. F., J. Am. Chem. Soc. 2014, 136, 8755 .

\section{Biosketches}




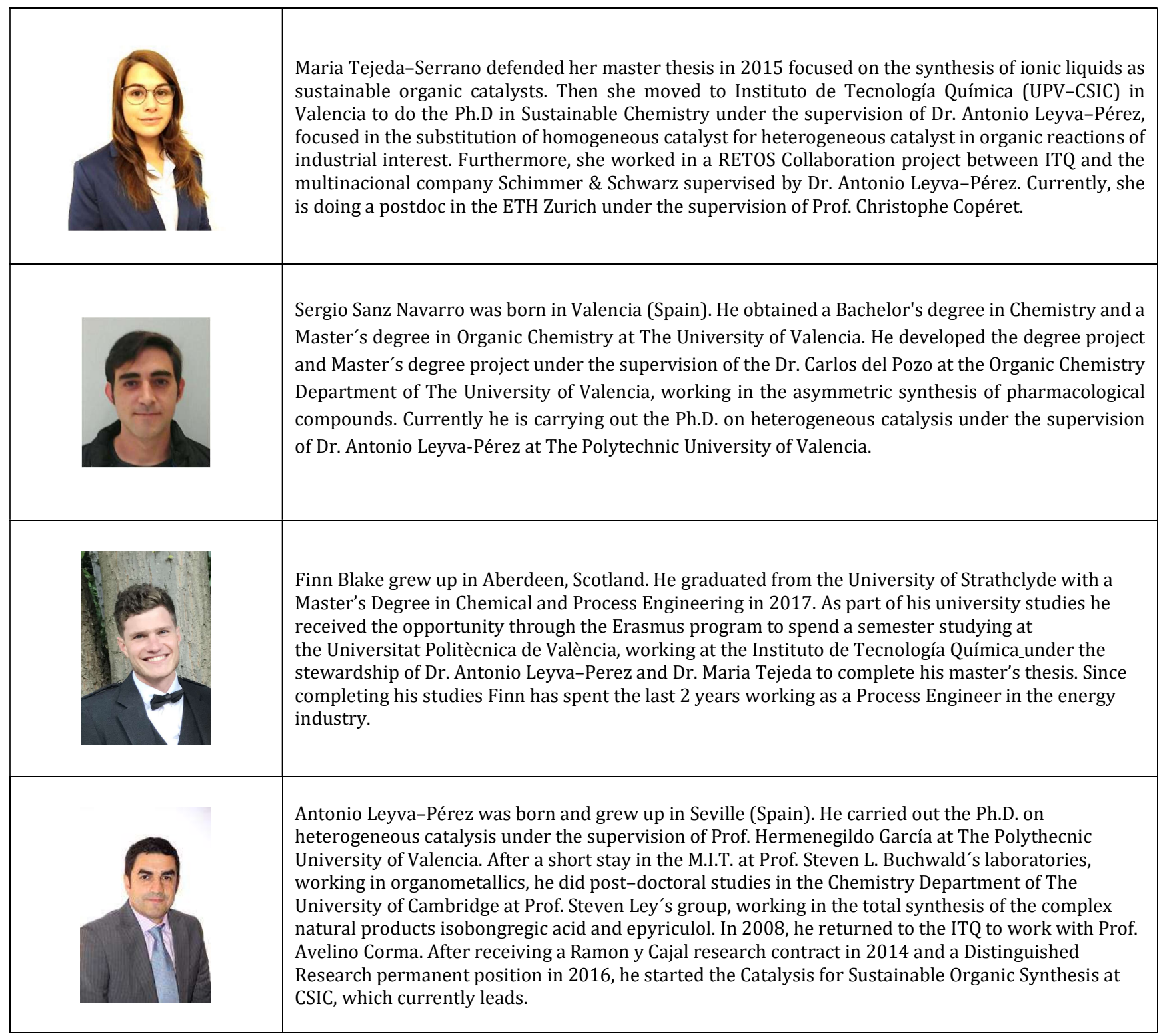

